\title{
The Distributional Consequences of Supply-Side Reforms in General Equilibrium*
}

\author{
Konstantinos Angelopoulos, Bernardo X. Fernandez, \\ James R. Malley
}

June 19, 2011

\begin{abstract}
Using a heterogeneous agent model allowing for different degrees of complementarity between capital, skilled and unskilled labour, this paper evaluates supply-side reforms consistent with lower public debt-toGDP in the long-run. We find that, relative to the other tax reforms, capital tax cuts lead to the highest aggregate welfare but are skillbiased and can thus increase inequality in the long-run. Depending on the elasticity of substitution between capital and unskilled labour, falls in the capital tax can result in welfare losses for unskilled workers, even in the absence of other frictions and increases in other forms of taxation. On the other hand, reductions in labour taxes can hurt the capitalists. We also show that including the transition period in the welfare evaluation lowers the inequality effects of capital tax reductions since the complementarity between capital and all labour inputs is higher in the short- than in the long-run. Finally, our results suggest that a form of "irrational exuberance" can arise after a tax cut under heterogeneous learning in the initial conditions after the reform.
\end{abstract}

JEL codes: E25, E62

\footnotetext{
${ }^{*}$ We would like to thank Chryssi Giannitsarou, Charles Nolan, Apostolis Philippopoulos, Peter Rosenkranz, and conference and seminar participants at the CESifo Area Conference on Macro, Money and International Finance 2011, the Scottish Economic Society Conference 2011, the Bank of Greece and the Center for Planning and Economic Research, Athens for helpful comments and suggestions. We are also grateful for financial support from the ESRC, Grant No. RES-062-23-2292, but the views expressed here are entirely our own. Address for correspondence: Jim Malley, Department of Economics, University of Glasgow, Adam Smith Building, Glasgow G12 8RT. E-mail jim.malley@glasgow.ac.uk.
} 


\section{Introduction}

There now exists a significant and growing literature on tax reforms in dynamic general equilibrium (DGE) models, largely focusing on the aggregate welfare benefits and the distributional consequences of permanent reductions in constant capital tax rates. Studies within the representative agent framework suggest that tax reforms which reduce capital taxation will produce welfare gains for the society, even if the tax burden is concurrently shifted to labour (see e.g. Lucas, 1990, Cooley and Hansen, 1992, Angelopoulos et al., 2011a). ${ }^{1}$ The aggregate welfare benefits from tax reforms that reduce capital taxation are also confirmed in models with heterogeneous agents (see e.g. Garcia-Mila et al., 2010). However, at the same time, heterogeneous agent models make clear that such reforms can have large redistributive effects that will disadvantage different groups in the society (see e.g. Domeij and Heathcote, 2004, Greulich and Marcet, 2008 and Garcia-Mila et al., 2010). ${ }^{2}$

The literature using heterogeneous agent models has also considered different types of market incompleteness to demonstrate the distributional effects of tax reforms and, in particular capital tax cuts (see e.g. the papers reviewed in Garcia-Mila et al., 2010). For the class of models that remains closer to the neoclassical models of Judd (1985) and Chamley (1986), the cost to workers from a capital tax cut generally arises from an increase in labour taxes needed to maintain the level of tax revenue. In contrast, the benefits take the form of increased labour productivity delivered by the increase in the capital stock. In addition, the inclusion of the transition period in the welfare evaluation of the reforms is crucial. This is because the benefits associated with the above trade-off materialise later in the lifetime of the worker, whereas the costs have an immediate effect (see e.g. Greulich and Marcet, 2008 and Garcia-Mila et al., 2010).

However, there are strong reasons to believe that a reduction in capital taxes, without further changes in other taxes, need not benefit all agents if there is heterogeneity in work skills and the production structure exhibits

\footnotetext{
${ }^{1}$ At the same time, at the aggregate level, there is also an important literature that examines optimal tax policy. The general message from Ramsey optimal taxation is that the tax rate on capital should be zero in the long-run (see e.g. Chamley, 1986, Chari et al., 1994 and Chari and Kehoe, 1999). This result, however, does not necessarily hold in models incorporating market failures (see e.g. Guo and Lansing, 1999), nor in models under time-consistent optimal taxation (see e.g. Klein et. al., 2008).

${ }^{2}$ Studies that take into account the redistributive effects of capital taxation in designing optimal taxation in heterogeneous agent models are fewer. In Judd (1985) and Chamley (1986), Ramsey-type optimal taxation leads to a zero tax on capital in the long-run. However, this result does not necessarily hold when time-consistent taxation is considered (see e.g. Krusell, 2002, and Angelopoulos et al., 2011b).
} 
capital-skill complementarities as suggested by e.g. Stokey (1996) and Krusell et al. (2000). When skilled labour complements capital more than unskilled, capital-augmenting policies will be skill-biased and will thus increase the wage premium and inequality. ${ }^{3}$ In addition, the importance of the transition path after a tax reform suggests that considering alternative expectation generating mechanisms is also useful. For instance, Giannitsarou (2006) has shown that capital tax cuts, which necessitate learning on the part of the agents towards the new equilibrium, can reduce the desirability of such reforms. However, Giannitsarou (2006) worked in a representative agent framework and thus did not consider the case where agents might have heterogeneous initial conditions for learning after the reform.

With the above background in mind, this paper aims to welfare-evaluate changes in income tax rates for different types of agents, in a model that allows for capital-skill complementarity and dynamics that can be influenced by heterogeneity with respect to initial conditions for learning. To isolate the effects of changes in each tax rate on all agents, we consider changes in tax rates that are not revenue neutral. Instead, given its current policy relevance, we consider tax reforms consistent with a lower steady-state debtto-GDP ratio.

We calibrate our model to the UK economy, with the aim of obtaining a realistic assessment of the likely costs and benefits of tax reforms for the different agents. Our modeling permits us to capture key features of heterogeneity. Following the literature on credit constraints and income inequality (see e.g. Galor and Zeira, 1993, Benabou, 1996 and Aghion and Howitt, 1998), financial intermediation costs allow our model to generate heterogeneity in savings, which is consistent with the UK data. In addition, we use a constant elasticity of substitution (CES) specification for the production function, following e.g. Stokey (1996) and Krusell et al. (2000), which assumes different degrees of complementarity with capital for skilled and unskilled labour. This allows our calibrated model to produce factor input elasticities and a wage premium that are in line with empirical studies.

We relax the assumption of rational expectations so that we can also consider an adaptive learning environment. This allows us to include an additional source of heterogeneity, in the form of the initial beliefs of the agents who need to learn the equilibrium laws of motion. This corresponds to an unequal distribution of information after the reform in the economy and, as far as we know, has not yet been considered in the tax reform literature.

By first focusing on the long-run, we are able to show that the structure

\footnotetext{
${ }^{3}$ See e.g. Hornstein et al. (2005) for a review of the literature and empirical evidence on factor- and sector-specific technologies and inequality.
} 
of the production and, in particular, the complementarity between labour and capital matters crucially when evaluating the welfare benefits of tax reforms for the different agents. Relative to the other tax reforms, capital tax reductions lead to the highest aggregate welfare but are skill-biased and can thus increase inequality. Similarly, reductions in labour income taxes can also disproportionately favour either skilled or unskilled labour. We find that for a range of empirically plausible elasticities of substitution between capital and unskilled labour, a reduction in the capital tax, or indeed any income tax, need not be Pareto improving. In fact, when capital and unskilled labour are sufficiently substitutable, a reduction in the capital tax leads to a crowding out of unskilled labour in the production, which clearly hurts the workers. These results complement and strengthen the analysis in Garcia-Mila et al. (2010), since the cost to the unskilled workers does not arise from an increase in the labour taxes in our policy experiments. Moreover, these costs remain in the long-run.

We next find that the inclusion of the transition period in the welfare evaluation does not reverse the above results. However, in the case of a capital tax cut, it decreases the inequality effects of this reform. The winners from this reform, capitalists and skilled workers, benefit more from the higher capital stock as this is built up over time. In contrast, the losers, unskilled workers, are effectively indifferent. Therefore, including the initial periods helps to close the welfare gap between the agents, because, in general equilibrium, the complementarity between capital and all labour inputs is higher in the short-run than in the long-run.

Finally, we show that heterogeneity in learning matters. Consistent with the results in Giannitsarou (2006), under homogeneous initial conditions in learning, the convergence to the new steady-state is slower and this results in welfare costs for the agents after a capital tax cut. However, heterogeneity in initial conditions implies learning dynamics that result in paths for the economic variables that exhibit overshooting relative to the rational expectations solution. In this case, the errors that the learners make in the adjustment process amplify their reaction to the tax reform, so that there is a form of an "irrational exuberance", which is beneficial to all learners. Similarly, heterogeneous learning implies welfare gains for the other tax reforms considered. 


\section{Model}

In this section we construct a closed-economy DGE model comprised of a representative capitalist and representative skilled and unskilled workers who all consume output in the product market and supply labour in the factor market in return for labour income. The first two income groups, subject to intermediation costs, allocate savings to physical capital and government bonds in return for capital income whereas unskilled workers do not save. The representative firm is owned by the capitalist who hires (skilled and unskilled) labour services and leases physical capital from the factor market for which it pays the competitive wage and interest rate respectively. Finally, the government taxes economic activity, provides public spending and issues debt to balance its budget.

\subsection{Population composition}

The population size, $N$, is exogenous and constant. Among $N, N^{c}<N$ are identical capitalists, $N^{s}<N$ are identical skilled workers, and the rest, $N^{u}=N-N^{c}-N^{s}$, are identical unskilled workers. Capitalists are indexed by the subscript $c=1,2, \ldots, N^{c}$, skilled workers by $s=1,2, \ldots, N^{s}$ and unskilled workers by $u=1,2, \ldots, N^{u}$. There are also $N^{f}$ firms, $f=1,2, \ldots, N^{f}$. We assume that the number of firms equals the number of capitalists, $N^{c}=N^{f}$, and that each capitalist owns one firm. It is useful, for what follows, to define $N^{c} / N=n^{c}, N^{s} / N=n^{s}, N^{u} / N=n^{u}=1-n^{c}-n^{s}$ and $N^{f} / N=n^{f}$.

\section{$2.2 \quad$ Firms}

Each firm produces a single output, $Y_{t}^{f}$, using physical capital, $K_{t}^{f}$, and two distinct types of labour, unskilled, $h_{u, t}^{f}$, and skilled, $h_{t}^{f}$, where skilled labour is relatively more complementary to capital than unskilled labour. The production function is given by a constant returns to scale (CRS) technology assumed to take a constant elasticity of substitution (CES) specification following e.g. Stokey (1996):

$$
Y_{t}^{f}=A_{t}\left[\rho\left(K_{t}^{f}\right)^{\nu}+(1-\rho)\left(h_{u, t}^{f}\right)^{\nu}\right]^{\frac{\alpha}{\nu}}\left[h_{t}^{f}\right]^{1-\alpha}
$$

where $A_{t}$ is exogenous stochastic productivity; $0<\alpha<1$, is the productivity of weighted capital and unskilled labor; $0<\rho<1$ is the weight attached to capital in the composite factor; and $0 \leq \nu \leq 1$, where $1 /(1-\nu)$ is the 
elasticity of substitution between capital and unskilled labor. ${ }^{4}$ The above CES form allows us to capture the capital-skill complementarity, which is considered to be a main driver of the skill premium and wage inequality (see e.g. Krusell et al., 2000 and Hornstein et al., 2005).

Each firm acts competitively, taking prices and policy variables as given, and maximises profits given by:

$$
\Pi_{t}^{f} \equiv Y_{t}^{f}-r_{t}^{k} K_{t}^{f}-w_{t} h_{t}^{f}-w_{u, t} h_{u, t}^{f}
$$

subject to the technology constraint given by (1); where $w_{t}$ and $w_{u, t}$ are, respectively, the wage rates of skilled and unskilled labour and $r_{t}^{k}$ is the interest rate on capital. ${ }^{5}$ The different roles in the production function for skilled and unskilled labour imply that there will be a skill premium for the former, in the sense that the ratio of $w_{t}$ to $w_{u, t}$ will be larger than unity. We will calibrate the production function so that the implied factor input elasticities and the resulting wage premium are in line with empirical studies.

\subsection{Budget constraints of capitalists}

The representative capitalist owns one firm and receives its profits. He also receives income from providing skilled labour services, $h_{c, t}$, to the labour market and income from interest on his accumulated stock of financial assets, in the form of capital, $K_{c, t}$, and government bonds, $B_{c, t}$. The interest rate on government bonds is given by $r_{t}^{b}$. All these sources of income are taxed. In particular, financial asset and profit income are taxed at the constant rate $\tau^{k}$, while labour income is taxed at the constant rate $\tau^{h}$.

We assume that those agents holding assets need to pay intermediation or transaction premia due to imperfections in capital markets. For instance, these premia can represent the costs of gathering extra information relating to legal issues, asset-specific government regulations, intermediation fees and so on. We follow Persson and Tabellini (1992) and Benigno (2009) and assume a quadratic cost function such that the capitalist incurs a cost of $\varphi_{c}^{k} K_{c, t}^{2}$ for holding physical capital and of $\varphi_{c}^{b} B_{c, t}^{2}$ for holding government bonds, where $\varphi_{c}^{b}, \varphi_{c}^{k}>0$ measures the size of the transaction costs. The presence of this capital market imperfection and of the associated transaction costs help the model to capture a feature of realism. However, their main contribution here is that they will allow us, as we shall see below, to capture household heterogeneity in asset holdings.

\footnotetext{
${ }^{4}$ Note that when $\rho=\nu=1$, the production function is of the standard Cobb-Douglas form in capital and skilled labour and when $0<\rho<1$ and $\nu=1$ capital and unskilled labor are perfect substitutes.

${ }^{5}$ Note that, in equilibrium, profits, $\Pi_{t}^{f}$, are driven to zero due to perfect competition.
} 
The capitalist uses his income for consumption, $C_{c, t}$, investment in capital, $I_{c, t}$, and investment in government bonds, $D_{c, t}$. He also receives average (per agent) transfers from the government, $\bar{G}_{t}\left(=G_{t} / N\right)$. Thus, his budget constraint is:

$$
\begin{aligned}
& C_{c, t}+I_{c, t}+D_{c, t}=\left(1-\tau^{k}\right)\left(r_{t}^{k} K_{c, t}+r_{t}^{b} B_{c, t}\right)+ \\
& +\left(1-\tau^{k}\right) \Pi_{t}^{f}+\left(1-\tau^{h}\right) w_{t} h_{c, t}+\overline{G_{t}}-\varphi_{c}^{b} B_{c, t}^{2}-\varphi_{c}^{k} K_{c, t}^{2}
\end{aligned}
$$

while the evolution of the stock of capital and government bonds, respectively, are given by:

$$
\begin{gathered}
K_{c, t+1}=(1-\delta) K_{c, t}+I_{c, t} \\
B_{c, t+1}=B_{c, t}+D_{c, t}
\end{gathered}
$$

where $0<\delta<1$ is a depreciation rate and $K_{c, 0}, B_{c, 0}>0$ are given.

\subsection{Budget constraints of skilled workers}

The problem of the skilled worker is similar to the capitalist's, except that he pays different transaction costs, so that the capital market imperfections affect him to a greater extent. We assume that firm ownership gives an insider advantage in financial transactions to the capitalist (due, for instance, to past experience, socioeconomic background, networks, etc.) and thus the size of the transaction costs is lower for the capitalist. The idea that capital market imperfections can explain heterogeneity has been extensively examined in the income inequality literature (see e.g. Galor and Zeira, 1993, Benabou, 1996, and Aghion and Howitt, 1998). Most of these models assume, for simplicity, that the intermediation cost is either infinite for some agents (and thus these agents are effectively excluded from the financial market) or zero. In this paper, we examine the case of non-zero, finite intermediation costs for both capitalists and skilled workers where $\varphi_{c}^{b}<\varphi_{s}^{b}, \varphi_{c}^{k}<\varphi_{s}^{k}$. We differentiate the skilled worker and capitalist even further by assuming that the former has lower initial holdings of capital and government bonds, i.e. $K_{s, 0}<K_{c, 0}$, $B_{s, 0}<B_{c, 0}$.

Accordingly, the budget constraints and the evolution equations for capital and government bonds for the $s^{t h}$ skilled worker are:

$$
\begin{gathered}
C_{s, t}+I_{s, t}+D_{s, t}=\left(1-\tau^{k}\right)\left(r_{t}^{k} K_{s, t}+r_{t}^{b} B_{s, t}\right)+ \\
+\left(1-\tau^{h}\right) w_{t} h_{s, t}+\bar{G}_{t}-\varphi_{s}^{b} B_{s, t}^{2}-\varphi_{s}^{k} K_{s, t}^{2} \\
I_{s, t}=K_{s, t+1}-(1-\delta) K_{s, t} \\
D_{s, t}=B_{s, t+1}-B_{s, t} .
\end{gathered}
$$




\subsection{Budget constraint of unskilled workers}

Unskilled workers differ from capitalists and skilled workers in two important respects. First, they start with zero initial holdings of assets and capital market imperfections result in them being excluded from the financial markets as in the models of Benabou (1996) and Aghion and Howitt (1998). ${ }^{6}$ Second, we assume that exclusion from capital markets does not allow them to acquire the skills to provide skilled labour services, so that their labour effort differs, in nature, from the labour effort of the other two types of agents. Evidence from the UK, introduced later, suggests that skill acquisition, in the form of University education, is indeed related to socioeconomic income group.

Thus, the budget constraint of the $u^{t h}$ unskilled worker is:

$$
C_{u, t}=\left(1-\tau^{u}\right) w_{u, t} h_{u, t}+\bar{G}_{t}
$$

where $0 \leq \tau^{u}<1$ is the tax rate on unskilled labour, $h_{u, t}$ is the labour supply and $C_{u, t}$ is the consumption.

\subsection{Utility function and optimal choices of agents}

Each type of household $i=c, s, u$ maximises:

$$
E_{0} \sum_{t=0}^{\infty} \beta^{t} u\left(C_{i, t}, h_{i, t}\right)
$$

subject to the relevant budget constraints given above; where $E_{0}$ is the conditional expectations operator.

We use the instantaneous utility function:

$$
u_{i, t}=\left(C_{i, t}, h_{j, t}\right)=\frac{\left[\left(C_{i, t}\right)^{\mu}\left(1-h_{i, t}\right)^{1-\mu}\right]^{1-\sigma}}{1-\sigma}
$$

where $0<\mu<1$ is the consumption weight in utility and $\sigma>1$ is the coefficient of relative risk aversion.

To maximise discounted lifetime utility, the representative capitalist chooses $\left\{C_{c, t}, h_{c, t}, K_{c, t+1}, B_{c, t+1}\right\}_{t=0}^{\infty}$ subject to $(3-5)$, the representative skilled worker chooses $\left\{C_{s, t}, h_{s, t}, K_{s, t+1}, B_{s, t+1}\right\}_{t=0}^{\infty}$ subject to $(6-8)$ and the representative unskilled worker chooses $\left\{C_{u, t}, h_{u, t}\right\}_{t=0}^{\infty}$ subject to (9).

\footnotetext{
${ }^{6}$ See e.g. Aghion et al. (1999) for a microeconomic rationalisation of credit constraints that do not allow agents to participate in asset markets.
} 


\subsection{Government budget constraint}

Following the literature on tax reforms (see e.g. Lucas, 1990, Cooley and Hansen, 1992, Giannitsarou, 2006, Garcia-Milà et al., 2010, and Angelopoulos et al., 2011a), we do not model government spending. Instead, government expenditure takes the form of transfers to the private agents, $G_{t}$. To finance these, it taxes income from labour and financial assets and issues government bonds, $B_{t}$. The budget constraint of the government is thus given by:

$$
\begin{aligned}
G_{t}+ & \left(1+r_{t}^{b}\right) B_{t}=B_{t+1}+N^{c}\left[\tau^{k}\left(r_{t}^{k} K_{c, t}+r_{t}^{b} B_{c, t}\right)+\tau^{h} w_{t} h_{c, t}\right]+ \\
& +N^{s}\left[\tau^{k}\left(r_{t}^{k} K_{s, t}+r_{t}^{b} B_{s, t}\right)+\tau^{h} w_{t} h_{s, t}\right]+N^{u}\left[\tau^{u} w_{u, t} h_{u, t}\right] .
\end{aligned}
$$

\subsection{Market-clearing conditions}

The market clearing conditions for the capital, bond, skilled and unskilled labour and product markets respectively are:

$$
\begin{gathered}
N^{f} K_{t}^{f}=N^{c} K_{c, t}+N^{s} K_{s, t} \\
B_{t}=N^{c} B_{c, t}+N^{s} B_{s, t} \\
N^{f} h_{t}^{f}=N^{c} h_{c, t}+N^{s} h_{s, t} \\
N^{f} h_{u, t}^{f}=N^{u} h_{u, t} \\
N^{f} Y_{t}^{f}=N^{c} C_{c, t}+N^{s} C_{s, t}+N^{u} C_{u, t}+N^{c}\left[K_{c, t+1}-(1-\delta) K_{c, t}\right]+ \\
+N^{s}\left[K_{s, t+1}-(1-\delta) K_{s, t}\right]+N^{c}\left(\varphi_{c}^{b} B_{c, t}^{2}+\varphi_{c}^{k} K_{c, t}^{2}\right)+ \\
+N^{s}\left(\varphi_{s}^{b} B_{s, t}^{2}+\varphi_{s}^{k} K_{s, t}^{2}\right)
\end{gathered}
$$

where (17) gives the aggregate resource constraint of the economy.

\subsection{Decentralised competitive equilibrium}

The decentralised competitive equilibrium (DCE) is defined when (i) households and firms optimize, taking prices and policy as given; (ii) all constraints are satisfied; and (iii) all markets clear. After the relevant substitutions, we summarise the DCE in the paths of the following variables: $\left(C_{c, t}, C_{s, t}, C_{u, t}, h_{c, t}, h_{s, t}, h_{u, t}, w_{t}, w_{u, t}, K_{c, t+1}, K_{s, t+1}, B_{c, t+1}, B_{s, t+1}, r_{t}^{k}, r_{t}^{b}\right)$ given the exogenously set stationary AR processes for technology and fiscal policy instruments which are discussed below. ${ }^{7}$ We define the relevant aggregate, economy-wide quantities as, $X_{t}$, for $X_{t}=\left\{C_{t}, I_{t}, K_{t}, B_{t}, Y_{t}\right\}$.

\footnotetext{
${ }^{7}$ To save space we have not reported the DCE system here but it will be provided on request.
} 


\subsection{The motion of productivity and fiscal policy in- struments}

Following the literature, we assume that the stochastic process determining $A_{t}$ is an exponential first-order Markov process:

$$
A_{t}=A_{0}^{\left(1-\rho^{a}\right)} A_{t-1}^{\rho^{a}} e^{\varepsilon_{t}}
$$

where $A_{0}>0$ is a constant, $0<\rho^{a}<1$ is the autoregressive parameter and $\varepsilon_{t} \sim \operatorname{iid}\left(0, \sigma^{2}\right)$ are random shocks to productivity.

Given that we wish to analyse the welfare implications of permanent tax regime changes, all tax rates are treated as exogenous constants, $0 \leq$ $\tau^{k}, \tau^{h}, \tau^{u}<1$. In the policy reforms that we will examine, the economy will start from the steady-state and will be subjected to an exogenous, permanent change in one or more tax instruments, holding the other policy instruments, including $G$, constant at the pre-reform steady-state values. We examine economic outcomes and welfare in the new steady and during the transition period to the new steady-state.

\section{Calibration and steady-state}

In Table 1, we next calibrate the structural parameters of the model so that its steady-state solution reported in Table 2 below reflects the main empirical characteristics of the UK economy. The calibration also provides empirical justification for the key modelling decisions made above.

\subsection{Population shares}

We first wish to map out agent heterogeneity and thus distinguish the three types of households by their differing shares in the population, $n^{i}$. According to the Family Resources Survey in 2008-2009, $28 \%$ of households do not have any savings, $53 \%$ have savings up to $£ 20,000$ and $19 \%$ have savings above $£ 20,000 .^{8}$ In light of this, since we assume that unskilled workers do not have savings, we set $n^{u}$ equal to $30 \%$. At the other end of the distribution, since we model capitalists as the income group with the highest share of savings and assets, we set $n^{c}$ to $20 \%$ implying that $n^{s}$ is $50 \%$. Other data providing an additional dimension by which unskilled workers differ from skilled workers and capitalists is that the former group offers a labour input that is lacking in skills. According to the Labour Force Survey of the Office for

\footnotetext{
${ }^{8}$ The survey is sponsored by the Department for Work and Pensions (see their Table 4.9 for the information reported here).
} 
National Statistics ${ }^{9}$, in 2003, $28 \%$ of the working population was employed in semi-routine and routine occupations, whereas the remaining share worked in supervisory, technical, professional and managerial occupations, which require an increasingly higher skilled labour input. Moreover, according to data from the Department for Education and Skills on the participation rates in higher education for different income groups, the participation ratio was about three times higher in the 1990s for the three highest, relative to the three lowest groups. ${ }^{10}$ Thus, there appears to be adequate support for associating skill with income group.

Table 1: Parameter Values

\begin{tabular}{lll}
\hline \hline parameter & value & definition \\
\hline $0<\alpha<1$ & 0.500 & productivity of composite input \\
$0<\rho<1$ & 0.400 & capital weight in composite input share \\
$0 \leq \delta \leq 1$ & 0.060 & depreciation rate on private capital \\
$\frac{1}{1-\nu}>0$ & 2.000 & capital to unskilled labour elasticity \\
$\varphi_{c}^{k}, \varphi_{c}^{b}>0$ & 0.001 & transaction costs, capitalists \\
$\varphi_{s}^{k}, \varphi_{s}^{b}>0$ & 0.005 & transaction costs, skilled workers \\
$0<\beta<1$ & 0.976 & rate of time preference \\
$0<\mu<1$ & 0.347 & consumption weight in utility \\
$\sigma>1$ & 2.000 & coefficient of relative risk aversion \\
$0<n^{c}<1$ & 0.200 & population share of capitalists \\
$0<n^{s}<1$ & 0.500 & population share of skilled workers \\
$0<G / Y<1$ & 0.330 & public spending share of output \\
$0<\tau^{h}<1$ & 0.300 & labour tax rate skilled \\
$0<\tau^{k}<1$ & 0.442 & capital tax rate \\
$0<\tau^{u}<1$ & 0.200 & labour tax rate unskilled \\
$A_{0}>0$ & 1.650 & constant parameter productivity \\
$0<\rho^{a}<1$ & 0.920 & AR(1) parameter productivity \\
$\sigma_{a}>0$ & 0.030 & std. dev. of productivity innovations \\
\hline
\end{tabular}

\subsection{Productivity}

We next turn to heterogeneity in productivity and returns to labour which governs the choice of the relevant production parameters. Following Stokey (1996), we set the weight of capital in the composite input share, $\rho$, to 0.4 and $\nu$ to 0.5 implying an elasticity of substitution between capital and unskilled labour, $1 /(1-\nu)$, of 2 . The latter is well within the range of estimated

\footnotetext{
${ }^{9}$ See http://www.statistics.gov.uk/STATBASE/Expodata/Spreadsheets/D7665.xls.

${ }^{10}$ See www.statistics.gov.uk/STATBASE/Expodata/Spreadsheets/D7308.xls .
} 
elasticities of substitution reported in the literature (see e.g. Stokey, 1996, and Hornstein et al., 2005, for reviews of these studies).

The productivity of the composite input in the production function, $\alpha$ and the constant term in the production function, $A_{0}$, are chosen so that, given the remaining parameters reported below, the model solution in the steady-state predicts a skill premium and a ratio of capital to GDP that is consistent with the UK data. In particular, we set $\alpha=0.5$ and $A_{0}=1.65$, which leads to a steady-state skill premium, defined as the log difference between the wage rate for skilled and unskilled labour, of $32 \%$. Also note that the ratio of the wage rates for skilled and unskilled labour is 1.38. These values are again broadly consistent with estimates for both the UK and the USA. For the UK, Walker and Zhu (2008) estimate a college premium (in $\log$ differences) of about $18 \%$ for males and $28 \%$ for females, while Machin (1996) computes the ratio of wages between non-manual and manual jobs in manufacturing that ranges between 1.3 and 1.5, from 1970 to 1990. For the USA, Hornstein et al. (2005) report a college premium, in terms of wage ratios, that ranges from about 1.47 in 1982 to 1.79 in 2000.

\subsection{Savings}

Heterogeneity in savings is controlled for, as explained in the previous section, by the parameters that govern transaction costs in the financial markets. Following the models in e.g. Galor and Zeira (1993), Benabou (1996) and Aghion and Howitt (1998), we set these costs to infinity for the unskilled workers, which implies that these agents do not have any savings. As said above, about $28 \%$ of the UK households do not save. Regarding the households with positive savings, data from the Family Resources Survey of 2008-2009 suggest that households in the highest saving bracket have five times higher savings than the other savers, on average. In terms of our model, this differ-

ence is applied to the representative capitalist and skilled worker by setting the transaction costs for the latter to be five times greater than the former. For simplicity, we set this cost in capital asset markets to be the same in the bond market. We chose the level of the transaction costs parameter, so that in combination with an annual depreciation rate, $\delta$, of $6 \%$, the total ratio of capital to GDP in the steady-state is about 2 . This also implies that the financial transaction costs as a share of GDP is about $0.5 \%$.

\subsection{Effective tax rates}

Effective average tax rates for capital and labour income are constructed by following the approach in Conesa et al. (2007). We use data from the 
National Accounts and the Public Sector, Taxation and Market Regulation databases (available from OECD Statistics), to obtain the series for 19702005. The average capital tax rate over the time period is $\tau^{k}=0.442$, while the average labour income rate is 0.27 . Using data from Social Trends 38, Office for National Statistics, we are able to approximate the progressivity of the UK income tax system at about $1.6 .^{11} \mathrm{~A}$ ratio of $\tau^{h} / \tau^{u}=1.6$, together with the requirement that the weighted average of the two tax rates equal the effective labour income tax rate, would imply that $\tau^{h}=0.304$ and $\tau^{u}=0.19$. However, the progressivity of income taxation probably overestimates the progressivity of labour income taxation, which is our interest here. This is because, in light of the data discussed, we would expect the higher income brackets to have more capital income compared to lower income brackets. On the other hand, the lower the progressivity ratio, the higher the implied value of $\tau^{u}$. We thus use a progressivity ratio of $\tau^{h} / \tau^{u}=1.5$ for the calibration, which guarantees that $\tau^{u}$ is equal to the base income tax rate. Accordingly, we approximate the lower tax rate, $\tau^{u}$, at $20 \%$, and the higher labour income tax rate, $\tau^{h}$, at $30 \%$.

\subsection{Parameters common to all agents}

We next approximate the rate of time preference, $\beta$, so that $1 / \beta$ is equal to 1 plus the ex-post real interest rate, where we use real interest rate data from OECD Main Economic Indicators, from 1970-2005. This gives a value 0.976 for $\beta$. Following Kydland (1995), we set $\mu$, the weight given to consumption relative to leisure in the utility function, equal to the average value of work versus leisure time, which is obtained using data on hours worked from the OECD Economic Outlook database, from $1970-2005 .{ }^{12}$ We also use a common value from the literature for the intertemporal elasticity of consumption, $1 / \sigma=0.5$ or $\sigma=2$.

Given that we will evaluate policies that reduce the debt-to-GDP ratio below, we calibrate the share of government spending in GDP, $G / Y$, to obtain a $B / Y$ ratio of $70 \%$ based on official forecasts for $2011-2013$ (see e.g. the PreBudget Forecast, June 2010, Office for Budget Responsibility $)^{13}$. Finally, the $A R(1)$ relation for the productivity process in (18) is estimated using TFP

\footnotetext{
${ }^{11}$ This is obtained by calculating the average income tax rate that applies approximately to the lower $30 \%$ and the upper $70 \%$ of the tax payers. We then add the national insurance contribution rate of $11 \%$ and calculate the ratio of these two effective average tax rates.

${ }^{12}$ To obtain this we divide total hours worked by total hours available for work or leisure, following Ho and Jorgenson (2001). They assume that there are 14 hours available for work or leisure per day with the remaining 10 hours accounted for by physiological needs.

${ }^{13}$ See http: //budgetresponsibility.independent.gov.uk.
} 
data from the Office for National Statistics, 1970-2005. The estimated values for $\rho^{a}$ and $\sigma_{a}$, are 0.92 and 0.03 respectively.

\subsection{Steady-state}

The steady-state solution of the model is given in Table 2 below in terms of the aggregate variables. The figures show that the capitalists consume in total $19.4 \%$ of total income (or about $22 \%$ of total consumption) ${ }^{14}$, skilled workers consume in total $45 \%$ of total income (or around $52 \%$ of total consumption) and unskilled workers consume in total $22.5 \%$ of total income (or approximately $26 \%$ of total consumption). In addition, the capitalists in total have around $67 \%$ of total savings and own about $67 \%$ of the capital and government bonds in the economy. As said above, the ratio of savings, $I_{c} / I_{s}$, and assets, $K_{c} / K_{s}$ and $B_{c} / B_{s}$, of the representative capitalist to the representative skilled worker, are equal to five. Note also that the net (after depreciation, tax and transaction costs) interest rates on capital and bonds, are given respectively by:

$$
\begin{array}{r}
\widetilde{r}_{k}=r^{k}\left(1-\tau^{k}\right)-\delta-2 \varphi_{c}^{k}\left(\frac{n^{c}}{n^{c}+n^{s}}\right) K_{c}-2 \varphi_{s}^{k}\left(\frac{n^{s}}{n^{c}+n^{s}}\right) K_{s} \\
\widetilde{r}_{b}=r^{b}\left(1-\tau^{k}\right)-2 \varphi_{c}^{b}\left(\frac{n^{c}}{n^{c}+n^{s}}\right) B_{c}-2 \varphi_{s}^{b}\left(\frac{n^{s}}{n^{c}+n^{s}}\right) B_{s}
\end{array}
$$

and are equal in the steady-state.

It is also worth noting that the labour supply elasticities of this model are more in line with microeconometric studies than in the standard aggregate RBC models (see e.g. King and Rebelo, 1999). The Frisch (or $\lambda$-constant) labour supply elasticity (see e.g. Browning et al., 1999) is 3.06 for capitalists, 2.15 for skilled and 2.21 for unskilled workers. The value for the capitalists suggest that, as expected, this group is the relatively least dependent on labour income.

The skill premium, measured as the log differences in the wage rates is about $32 \%$. In the steady-state, capitalists work considerably less than skilled and unskilled workers, who work more or less the same time (see the $h^{\prime} s$ in Table 2). Also note that in the steady-state $C_{c}=0.309, C_{s}=0.287$ and $C_{u}=0.239$. Thus in terms of welfare, $U$, higher consumption and lower work effort make the capitalists better off, followed by the skilled and

\footnotetext{
${ }^{14}$ This is calculated as $\frac{\left(N^{c} * C_{c}\right) / Y}{C / Y}=\left(N^{c} * C_{c}\right) / C$. The same formula is used below for similar quantities.
} 
unskilled workers respectively. The weighted average measure of aggregate or Benthamite lifetime utility, $U_{a}$, is also reported. ${ }^{15}$

Table 2: Steady-state (pre-reform)

\begin{tabular}{cccc}
\hline \hline variable & value & variable & value \\
$\frac{N^{c} * C_{c}}{Y}$ & 0.194 & $\frac{N^{c} * K_{c}}{Y}$ & 1.404 \\
$\frac{N^{s} * C_{s}}{Y}$ & 0.450 & $\frac{N^{s} * K_{s}}{Y}$ & 0.702 \\
$\frac{N^{u^{\prime} * C_{u}}}{Y}$ & 0.225 & $\frac{Y}{Y}$ & 2.106 \\
$\frac{C}{Y}$ & 0.868 & $\frac{N^{c^{c} * B_{c}}}{Y}$ & 0.467 \\
$\frac{N^{c_{I}} I_{c}}{N^{Y}}$ & 0.084 & $\frac{N^{s} * B_{s}}{Y}$ & 0.233 \\
$\frac{N^{s} * I_{s}}{Y}$ & 0.042 & $\frac{B}{Y}$ & 0.700 \\
$\frac{I}{Y}$ & 0.126 & $\widetilde{r_{k}}$ & 0.025 \\
$w$ & 1.015 & $\widetilde{r}_{b}$ & 0.025 \\
$w_{u}$ & 0.736 & $U_{c}$ & -71.494 \\
$h_{c}$ & 0.183 & $U_{s}$ & -76.953 \\
$h_{s}$ & 0.241 & $U_{u}$ & -81.649 \\
$h_{u}$ & 0.236 & $U_{a}$ & -77.270 \\
\hline
\end{tabular}

\section{Tax reforms}

In this section, we examine five different tax reforms that meet a debt-to-GDP target of $60 \%$ in the steady-state. The latter provides us with a common base for conducting the policy reforms. ${ }^{16}$ We start by changing the capital income tax rate, $\tau^{k}$, holding all other rates constant. Next we examine changes in the labour income tax rates, first on skilled labour, $\tau^{h}$, and second on unskilled labour, $\tau^{h}$, each implying that the progressivity of labour income taxation has been altered. We then examine the case where the government changes the effective average labour tax rate, i.e. $\tau^{h}$ and $\tau^{u}$ move proportionately, so that the progressivity in the labour income taxation remains unaffected. Lastly, we evaluate the distributional effects of varying all tax rates proportionately.

For each tax reform considered, we find the steady-state tax rate(s) required to obtain the target debt-to-GDP ratio and welfare-evaluate this tax reform in terms of its aggregate and distributional consequences in the long-

${ }^{15}$ The lifetime utility of agent $i$ in the steady-state is given by $U_{i}=\frac{\left(1-\beta^{T}\right)}{1-\beta} \bar{u}_{i}$, for $i=c, s, u$, where $\bar{u}_{i}$ is the welfare of $i$ calculated at the steady state using (11) and $T=1000$. Also note that $U_{a}=n^{c} U_{c}+n^{s} U_{s}+n^{u} U_{u}$.

${ }^{16}$ Given that we seek to evaluate the distributional effects of tax reforms and not the optimal size of the government or government debt, we take this debt target as given. Hence, we do not evaluate the potential welfare benefits from reducing the debt-to-GDP ratio, in the form of, for instance, lowering the cost of borrowing for the government and reassuring financial markets that there is no risk of default. 
run. ${ }^{17}$ We also study the transition path by starting the economy at its pre-reform steady-state, implementing the required permanent tax reform and then simulating the response of economy until it reaches the new steadystate. This allows us to calculate lifetime welfare under both rational and bounded rational expectations.

\subsection{Laffer curves in tax revenue and debt}

Prior to undertaking the welfare analysis, it is first useful to demonstrate the general equilibrium effects of tax changes on factor returns and quantities by examining the effect of tax changes on the tax revenue from all tax bases. The relationship between the tax revenue from a particular tax base and the associated tax rate is, in general, given by a Laffer curve (see e.g. SchmittGrohé and Uribe, 1997). In our model, changing a tax rate can lead to either increases or decreases in the tax revenue collected from this tax base, depending on whether the economy is on the upward or downward slopping part of the curve, respectively. In the CES production function with capitalskill complementarity that we employ, a tax rate change will have spillover effects to the tax revenue collected from the other tax bases. For instance, an increase in the capital tax rate will decrease the capital supply, but will tend to increase or decrease the supply of unskilled labour, depending on whether the latter substitutes for or complements capital in production. Thus, the tax revenue collected from the tax base of unskilled labour income can either rise or fall after an increase in the capital tax.

As an illustration, we plot the Laffer curves associated with changes in $\tau^{k}$ in Figure 1. The $B / Y$ curve (lower-right panel) indicates that the target for the debt to GDP ratio can be obtained by either increasing or decreasing $\tau^{k}$ to $47.4 \%$ or $28.4 \%$, respectively. The relationship between tax revenue from assets and the capital tax rate (upper-right panel) shows that the economy is near the peak of this Laffer curve. Increasing $\tau^{k}$ only marginally increases the tax revenue collected from capital, while drops in $\tau^{k}$ decrease tax revenue from this source. However, the upper-left and upper-middle panels in the Figure suggest that decreases in $\tau^{k}$ crowd-in both skilled and unskilled labour and thus tax revenue from these sources increases. Thus the UK economy appears to be on the wrong side of the total tax revenue and debt Laffer

\footnotetext{
${ }^{17}$ Note that a lower level of debt in the steady-state implies that there will also be a reduction in interest payments on debt and thus in total government spending, assuming, as we do here, that the remaining components of government spending do not change. Hence, tax reforms consistent with a lower level of steady-state debt will need to generate a lower level of total tax revenue.
} 
curves with respect to $\tau^{k}{ }^{18}$

[Figure 1 about here]

The results for the Laffer curves associated with the remaining tax instruments are, in general, similar. ${ }^{19}$ They also imply that, consistent with the analysis in Schmitt-Grohé and Uribe (1997), for a given level of debt, when a tax rate is the variable that is chosen to satisfy the government budget constraint, there can be two long-run solutions. ${ }^{20}$ To rank order these equilibria at both the aggregate level and for each type of agent, across different tax reforms, we next undertake a welfare analysis.

\subsection{Evaluation of tax reforms in the long-run}

In Table 3 we summarise the tax changes required to obtain steady-state equilibria that are consistent with the target $B / Y$ ratio of $60 \%$. Given the Laffer curves in tax revenue and debt discussed above, this target is consistent with both increases and decreases in tax rates.

Table 3: Tax reforms and steady-state equilibria $(\mathrm{B} / \mathrm{Y}=0.6)$

\begin{tabular}{lcccccc}
\hline \hline & \multicolumn{3}{c}{ fall in tax rates } & \multicolumn{3}{c}{ rise in tax rates } \\
& $\tau^{k}$ & $\tau^{h}$ & $\tau^{u}$ & $\tau^{k}$ & $\tau^{h}$ & $\tau^{u}$ \\
\hline base (B/Y=0.7) & 0.442 & 0.300 & 0.200 & 0.442 & 0.300 & 0.200 \\
$\tau^{k}$ & 0.284 & & & 0.474 & & \\
$\tau^{h}$ & & 0.289 & & & 0.681 & \\
$\tau^{u}$ & & & 0.173 & & & 0.830 \\
$\tau^{u}, \tau^{h}$ & & 0.291 & 0.194 & & 0.685 & 0.456 \\
$\tau^{u}, \tau^{h}, \tau^{k}$ & 0.424 & 0.288 & 0.192 & 0.578 & 0.393 & 0.262 \\
\hline
\end{tabular}

We next calculate the welfare for each agent at the steady-state of these equilibria and present, in Table 4, the welfare gains/losses relative to the pre-reform economy. To calculate these welfare changes, we follow Lucas (1990) and compute the percentage extra consumption that an individual would require so as to be equally well off between the two regimes. This is

\footnotetext{
${ }^{18}$ This is consistent with data on effective capital tax rates, which suggest that capital taxation in the UK is much higher than the rest of Europe and the USA (see e.g. Angelopoulos et al., 2011a, for a discussion of these data).

${ }^{19}$ These are not presented to save space but will be made available on request.

${ }^{20} \mathrm{~A}$ critical condition for this is that a Laffer curve exists with respect to total tax revenue. Further note that Schmitt-Grohé, and Uribe (1997), also discuss the parameter range under which some of these equilibria can be indeterminate. For our model and the calibrated parameters for the UK, all solutions obtained below are saddle-path stable.
} 
defined as:

$$
\xi_{i}=\left(\frac{U_{i, s s}^{p o s t}}{U_{i, s s}^{p r e}}\right)^{\frac{1}{\mu(1-\sigma)}-1}
$$

for each agent $i=c, s, u$, where $s s$ denotes welfare calculated in the steadystate.

The first observation regarding the results in Table 4 is that, as expected, welfare is always reduced for all agents for increases in tax rates. Therefore, we do not consider these equilibria further in the analysis which follows.

Table 4: Steady-state welfare gains/losses relative to pre-reform economy

\begin{tabular}{lcccccc}
\hline \hline & \multicolumn{2}{c}{$\xi^{\prime} s$ for fall in tax rates } & \multicolumn{3}{c}{$\xi^{\prime} s$ for rise in tax rates } \\
& Capitalist & Skilled & Unskilled & Capitalist & Skilled & Unskilled \\
\hline$\tau^{k}$ & 0.199 & 0.126 & 0.004 & -0.047 & -0.028 & $-3.7 \mathrm{e}-04$ \\
$\tau^{h}$ & $-9.7 \mathrm{e}-05$ & 0.007 & 0.003 & -0.301 & -0.302 & -0.112 \\
$\tau^{u}$ & -0.007 & $-8.9 \mathrm{e}-04$ & 0.018 & -0.095 & -0.094 & -0.297 \\
$\tau^{u}, \tau^{h}$ & -0.002 & 0.006 & 0.006 & -0.318 & -0.314 & -0.217 \\
$\tau^{u}, \tau^{h}, \tau^{k}$ & 0.023 & 0.023 & 0.008 & -0.223 & -0.175 & -0.059 \\
\hline
\end{tabular}

Regarding the fall in tax rates, note that a proportional reduction in all tax rates in the final row improves welfare for all agents. However, there are different effects on the agents from dropping one tax rate at the time. For instance, a reduction in $\tau^{k}$ appears to be Pareto improving in the long-run. ${ }^{21}$ In contrast, reductions in $\tau^{u}$ or $\tau^{u}$ and $\tau^{h}$ combined hurt the capitalists and are thus not Pareto improving. In addition, benefits from a reduction in $\tau^{k}$ are far bigger for the capitalists and skilled workers, compared to unskilled workers. The key to interpreting these results lies in the structure of production. As discussed above when analysing Figure 1, a fall in $\tau^{k}$ increases the capital stock and this raises the productivity of both types of labour, so that labour supply and labour income are increased. Therefore, workers also gain by a reduction in the capital tax. This positive productivity spillover effect is also at the heart of the zero long-run optimal capital tax results in models that assume a relatively high complementarity between the labour input of the worker and capital stock (e.g., as in models using Cobb-Douglas production functions). However, consistent with Krusell et al. (2000), a higher capital stock benefits skilled labour more than unskilled, so that the wage premium increases to $47 \%$ (implying a wage ratio of 1.59 ) after the reform. In contrast, reductions in $\tau^{u}$ or $\tau^{u}$ and $\tau^{h}$ result in increases in unskilled labour,

\footnotetext{
${ }^{21}$ The fall in $\tau^{h}$ is also effectively Pareto improving since $\xi$ for the capitalists is essentially zero.
} 
which increases skilled labour but crowds out capital, leading to lower capital income. $^{22}$

The general message from the above analysis is that the complementarity and/or substitutability between factor inputs is important when assessing the effects of tax reforms. This finding is consistent with related research which has emphasised the importance of different patterns of production and sectorand factor-specific technical change on inequality (see e.g. Hornstein et al., 2005, for a review). Here, the tax reform plays a similar role to factor-specific technological progress given the way it affects factor returns and productivity. By reducing $\tau^{k}$ or $\tau^{h}$ the government is effectively introducing a skill-biased change, while reductions in $\tau^{u}$ favor the unskilled.

\subsubsection{Structure of production}

To further explore the role of the production structure and, in particular, of the elasticity of substitution between capital and unskilled labour, we re-calibrate the model and repeat the above analysis for a range of these elasticities. We consider values of $\nu$ between 0.5 and 0.6 , as beyond 0.6 , the model solution implies wage premia that are not consistent with the data (e.g. at $\nu=0.7$, the skill premium is about $74 \%$ ). In each case, we re-calibrate government spending so as to have a pre-reform economy with debt-to-GDP ratio of $70 \%$, but otherwise leave the calibration in Table 1 unchanged.

We focus on the tax reforms that involve, ceteris paribus, reductions in the capital tax given its prominence in the tax reform and policy literatures. $^{23}$ The results for the welfare gains/losses for all agents are shown on Figure 2 and suggest that reductions in the capital tax are not always Pareto improving.

[Figure 2 about here]

For plausible values of $\nu$ (i.e. above 0.525 ) and of the elasticity of sub-

\footnotetext{
${ }^{22}$ Note that by reducing interest payments in the steady state, the tax cuts considered here imply an additional channel through which they affect the agents differently. Namely, debt in the steady-state represents assets to skilled workers and capitalists. Hence, its reduction implies, ceteris paribus, a reduction in an income source for these two agents, but not for unskilled workers. This hurts capitalists and skilled workers, especially when the tax rate on unskilled labour falls.

${ }^{23}$ Not that, for higher values of $\nu$, reducing $\tau^{h}$ increases welfare for all agents. Skilled labour complements both capital and unskilled labour and thus tends to increase both. As the elasticity of substitution between capital and unskilled labour increases, capital can be used more easily to complement skilled labour and this benefits the capitalists, while still allowing the unskilled workers to benefit from the complementarity between skilled and unskilled labour. For the symmetrically opposite reasons, the cost to the capitalist increases for lower values of $\nu$.
} 
stitution between capital and unskilled labour, $1 /(1-\nu)$, (i.e. above 2.11), workers lose from a reduction in the capital tax. The reason is that, as capital and unskilled labour become better substitutes, the latter is replaced by capital in the production process when the returns to capital increase. The idea that reductions in capital taxation imply welfare losses for a share of the population that does not hold capital has also been discussed in the literature on tax reform (see e.g. Garcia-Mila et al., 2010, and Greulich and Marcet, 2008). However the factors generating this finding are different from those at play in our model. In particular, these studies examine revenue neutral tax reforms whereby labour taxes are increased to compensate for the loss in tax revenue associated with the fall in capital taxes.

\subsection{Evaluation of tax reforms over the lifetime}

We next evaluate the aggregate and distributional effects of the above tax reforms over the lifetime of the agents, including the transition period, paying particular attention to how agents form expectations after the reform. First, we evaluate the lifetime welfare of all agents, ${ }^{24}$ as they converge to the postreform steady-state starting from the current economy, assuming rational expectations (RE). In this case, the agents adjust their choices to the new tax rates immediately when the reform takes place.

Second, we evaluate lifetime welfare assuming an adaptive learning (AL) environment in which the agents have fully learned the pre-reform rational expectations solution but now must learn the coefficients of their reduced form policy functions associated with the post-reform economy by using a recursive least squares (RLS) learning algorithm, which is widely used in the AL literature. Here, we examine two scenarios which determine the initial conditions for learning. In the first, which serves to contextualise our results relative to the literature, we follow e.g. Giannitsarou (2006) and Evans et al. (2009) and assume that the agents start learning using the reduced form coefficients that correspond to the pre-reform economy. In the second, we assume that there is heterogeneity in the initial conditions used for learning, capturing, for instance, unequal information regarding the tax reform, so that a subset of the population - i.e. the capitalists - can make a better initial guess regarding the coefficients in its policy function. ${ }^{25}$

It is worth noting that in the first scenario of AL with homogeneous initial beliefs, the welfare effects of all tax reforms for all agents are effectively the

\footnotetext{
${ }^{24}$ We calculate conditional welfare or discounted lifetime utility using equation (10) and a time horizon of 1000 periods.

${ }^{25}$ See the Appendix for the model solution under rational expectations and learning and for details on how the initial conditions for learning are set.
} 
same as under the RE solution, consistent with the results in Giannitsarou (2006). ${ }^{26}$ Hence, to save space, we do not discuss results from this solution further and only present results from rational expectations $\left(\xi_{r e}\right)$ and AL with heterogeneous initial beliefs $\left(\xi_{a l}\right)$ henceforth heterogenous learning.

The results for the lifetime welfare gains/losses for each agent under rational expectations and heterogenous learning are shown in Tables 5 and 6 for each tax reform considered. To quantify the importance of the latter for welfare, we also calculate the cost of the heterogeneous learning, in terms of the consumption supplement, compared to the RE solution. This is defined as $\zeta$ in Tables 5 and 6 .

Table 5: Lifetime welfare (lower tax rates)

\begin{tabular}{rcccccccccc}
\hline \hline & \multicolumn{3}{c}{$\tau^{k}=0.284$} & \multicolumn{3}{c}{$\tau^{h}=0.289$} & \multicolumn{3}{c}{$\tau^{u}=0.173$} \\
\hline & $\xi_{r e}$ & $\xi_{a l}$ & $\zeta$ & $\xi_{r e}$ & $\xi_{a l}$ & $\zeta$ & $\xi_{r e}$ & $\xi_{a l}$ & $\zeta$ \\
$c$ & 0.078 & 0.088 & -0.009 & -0.002 & -0.002 & $-1.1 \mathrm{e}-04$ & -0.008 & -0.008 & $-4.9 \mathrm{e}-05$ \\
$s$ & 0.071 & 0.087 & -0.014 & 0.006 & 0.006 & $-7.8 \mathrm{e}-05$ & -0.002 & -0.001 & $-3.6 \mathrm{e}-05$ \\
$u$ & 0.008 & 0.011 & -0.003 & 0.003 & 0.003 & $-6.3 \mathrm{e}-06$ & 0.018 & 0.018 & $-2.9 \mathrm{e}-06$ \\
$a$ & 0.052 & 0.062 & -0.001 & 0.004 & 0.004 & $-6.0 \mathrm{e}-05$ & 0.003 & 0.003 & $-2.8 \mathrm{e}-05$ \\
\hline
\end{tabular}

Table 6: Lifetime welfare (combined lower tax rates)

\begin{tabular}{crrcccc}
\hline \hline \multicolumn{4}{c}{$\tau^{u}=0.194, \tau^{h}=0.291$} & \multicolumn{3}{c}{$\tau^{u}=0.192, \tau^{h}=0.288}$, \\
& \multicolumn{3}{c}{$\tau^{k}=0.424$} \\
\hline$i$ & $\xi_{r e}$ & $\xi_{a l}$ & $\zeta$ & $\xi_{r e}$ & $\xi_{a l}$ & $\zeta$ \\
$c$ & -0.004 & -0.003 & $-9.4 \mathrm{e}-05$ & 0.008 & 0.008 & $-6.2 \mathrm{e}-04$ \\
$s$ & 0.005 & 0.005 & $-6.9 \mathrm{e}-05$ & 0.016 & 0.016 & $-4.7 \mathrm{e}-04$ \\
$u$ & 0.006 & 0.006 & $-5.6 \mathrm{e}-06$ & 0.009 & 0.009 & $-4.3 \mathrm{e}-05$ \\
$a$ & 0.004 & 0.004 & $-5.4 \mathrm{e}-05$ & 0.012 & 0.012 & $-3.6 \mathrm{e}-04$ \\
\hline
\end{tabular}

\subsubsection{Rational expectations}

We first compare lifetime welfare gains/costs in Tables 5 and 6 to the corresponding steady-state values in Table 4 under RE. Generally, tax cuts result in smaller (bigger) welfare gains (losses) when calculated over the lifetime relative to the long-run for capitalists and skilled workers. In contrast, the welfare figures are roughly the same over both time horizons for the unskilled

\footnotetext{
${ }^{26}$ Note it is only when the tax reform was accompanied by a negative shock to TFP that the rational expectations and learning transition paths differed more substantially in Giannitsarou (2006). The results reported below correspond to a non-stochastic case, when there is a zero initial shock to the model at the time of the reform. A "stochastic" transition from the old to the new steady state (obtained by averaging over 2500 simulations) produced transition paths that are very similar to those reported below.
} 
workers. ${ }^{27}$ Consistent with the literature, the results also indicate that the larger benefits in terms of aggregate welfare are obtained by capital tax cuts.

Hence, we focus again on the capital tax reduction as an illustration of the importance of the transition path and heterogeneous learning for the welfare evaluation of tax reforms. To this end, we plot in Figure 3 the pre-reform steady-state in percent deviations from the post-reform steady-state and the transition paths of output, inputs (capital and hours) and consumption by agent, under RE and heterogeneous learning. The paths of consumption and hours are important as these will ultimately determine welfare for each agent. $^{28}$

\section{[Figure 3 about here]}

The fall in capital taxes implies an increase in the capital stock and the economy gradually converges to the new equilibrium. All labour inputs initially increase above the new steady-state and then converge to it. As the owners of the capital stock become wealthier, given the lower capital tax, they tend to supply less labour, ceteris paribus. At the same time, the higher return to capital also increases the return to labour, given the complementarities in the production function discussed above, so that all agents tend to increase labour supply, ceteris paribus. Of course, higher returns to labour also have an implicit income effect, that tends to reduce, ceteris paribus, labour supply.

In general equilibrium, the substitution effect in labour supply is at first very strong, which results in the initial increase in labour hours. However, as capital is built up, the income effect dominates and labour supply falls. In the new steady-state, the above trade-offs imply that the capitalists supply less labour compared with the pre-reform equilibrium. In contrast, skilled and unskilled workers supply more hours, as the income effect for the latter two groups is smaller, given their smaller capital holdings. Note also that, as we saw previously, unskilled labour is substituted by capital in the new steady-state, provided that the elasticity of substitution between these two inputs is high enough. In this case, after the initial sharp increase, the labour effort of unskilled workers falls towards the new steady-state. Overall, the dynamic analysis indicates that, in general equilibrium, the complementarity

\footnotetext{
${ }^{27}$ Note that for the tax reforms considered in Garcia-Milla et al. (2010) and Greulich and Marcet (2008), the welfare losses to the workers from a capital tax cut are higher in the transition period to the new steady state. This is because the cost, in the form of a higher labour income tax, has an immediate effect after the reform, while the benefits, in the form of increased productivity, are stronger in the long run, as the capital stock is built up.

${ }^{28}$ To save space we do not present the Figures associated with the remaining tax reforms reported in Tables 5 and 6 but these are available on request.
} 
between capital and all labour inputs is higher in the short-run, compared with the long-run. Naturally, since all inputs increase after the tax cut, so does output.

For the capitalist and the skilled worker, consumption is at its highest in the new steady-state, while leisure is also higher compared with most of the transition. Note, in fact, that the initial periods after the reform are followed by a reduction in consumption for capitalists and skilled workers, as they shift their resources over time through capital investment, to exploit the higher returns to capital. The simultaneous fall in consumption and leisure time implies, in fact, that capitalists and skilled workers are worse-off in the first periods after the capital tax cut. Therefore, including the transition path in the welfare analysis reduces the welfare gains of the tax reform for these agents.

For the unskilled worker, consumption is at its highest immediately after the reform, which explains why including the transition in the welfare evaluation does not decrease welfare for this type of agent. The reason is that the only consumption effect for the unskilled worker takes place via the increase in labour income, which is higher immediately after the transition for all agents, given the increase in labour supply at this stage. In the long-run, labour income converges to a lower level, compared with the first periods after the reform. However, the capitalist and skilled worker also benefit from the higher capital income, as the capital stock reaches the new desired post-reform level. Obviously, the unskilled worker does not benefit from the higher capital stock.

\subsubsection{Heterogeneous learning}

Finally, we evaluate the importance of learning under heterogeneous initial beliefs. In particular, the skilled workers initiate their learning by using the coefficients that correspond to RE solution consistent with the old, pre-reform steady state. In contrast, capitalists are able to guess, immediately after the reform, the coefficients that correspond to the RE solution consistent with the new steady state. ${ }^{29}$ However, both agents' expectations will be erroneous, because the actual economy, as determined by the interaction of their choices, is neither in the pre- nor in the post-reform RE equilibrium. In Figure 3, it can be seen that as the agents revise their errors along the transition path, the general equilibrium response to the tax reform includes an overshooting

\footnotetext{
${ }^{29}$ Note that, as in the RE solution of the model for our calibration, all the policy experiments under the described setup yield stationary and locally E-stable solutions. In other words, these reforms are effectively learnable (see, e.g. Evans and Honkapohja, 2001, and Honkapohja and Mitra, 2006).
} 
relative to the rational expectations case. This is different from the case of homogeneous learning, where adaptive learning generally implies a slower convergence to the new equilibrium (see e.g. Giannitsarou, 2006). Therefore, contrary to homogeneous learning, which dampens the reaction to the tax reform, the errors that heterogeneous learners make amplify their reaction.

The intuition for this result is consistent with Giannitsarou's (2006) observation that positive shocks that coincide with the reform generate a "boost in optimism" that accelerates convergence to the new steady state and capital and output can overshoot in the early periods under learning as compared to RE. In our case, the overshooting is obtained in the absence of such shocks. Both capitalists and skilled workers are learners but given our assumptions regarding heterogeneity in initial beliefs, the former already know their own post-reform RE coefficients. Hence they realise that returns on investment are higher in the new steady state, so they start immediately investing more and accumulating capital faster. In contrast, the skilled workers are still using the pre-reform coefficients and have no information about the effects of the new regime. Hence, the increased activity they perceive due to the decision of the capitalists appears to them as very high forecast errors, as they keep discovering that total capital is higher than the their latest forecast. These, in effect, act as successive positive shocks which lead them to a faster accumulation of capital than if they were fully rational.

This overshooting from skilled workers implies that capitalists have also made a forecast error, as actual capital is in fact higher than their forecasted capital that would be consistent with the RE path. Hence, they also "correct" their behaviour accordingly by investing more, and thus by overshooting themselves. Thus, heterogeneity in initial conditions appears to create forecast errors that effectively act as positive shocks in the early periods, as the actual capital stock is higher than what was expected. This effect is higher for the skilled workers, as can be seen in Figure 3.

Therefore, heterogeneous learning leads to a form of "irrational exuberance" which disappears in the long-run as beliefs gradually converge to the RE solution. However, in the particular case of a capital tax cut, this helps to increase the welfare for all agents along the transition path, relative to the case of rational expectations (see, e.g. the relevant $\zeta$ figures in Table 5). The difference between rational expectations and heterogeneous learning is very small for the remaining tax reforms, given that the change in tax rates is also small. Naturally, for bigger tax reforms, the quantitative effects of heterogeneous initial beliefs in learning are bigger. 


\section{Conclusions}

Using a heterogeneous agent model allowing for different degrees of complementarity between capital, skilled and unskilled labour, we have evaluated supply-side reforms consistent with lower public debt-to-GDP in the long-run. To implement these reforms, we calibrated the model so that the steady-state represented the current UK economy and then simulated permanent changes in tax rates, starting from the pre-reform steady-state. We calculated welfare for each agent in the new steady-state and over the transition period to the post-reform steady-state.

Our results suggest that, relative to the other tax reforms, capital tax reductions lead to the highest aggregate welfare but are skill-biased and can thus increase inequality in the long-run. Depending on the elasticity of substitution between capital and unskilled labour, falls in the capital tax can result in welfare losses for unskilled workers, even in the absence of other frictions and increases in other forms of taxation. On the other hand, reductions in labour taxes can hurt the capitalists. Thus, tax reforms should be accompanied by a careful evaluation of the production structure to identify the groups that are mostly likely to see their returns reduced so that appropriate redistributive policies can be considered. Our findings also show that including the transition period in the welfare evaluation lowers the inequality effects of capital tax reductions since the complementarity between capital and all labour inputs is higher in the short- than in the long-run. Finally, our results suggest that a form of "irrational exuberance" can arise after a tax cut under heterogeneous learning in the initial conditions after the reform.

While we have not considered redistributive policies, we expect them to be more effective if they aim to raise the productivity of factor inputs, rather than simply redistribute income towards the income groups that are not favoured by the reform. A careful evaluation of such policies would be an obvious extension to this work. Our analysis also suggests that useful insights regarding the design of optimal tax-spending policies might be obtained under production structures that allow for different complementarities between factor inputs. We leave these issues for future research. 


\section{References}

[1] Aghion, P. and Howitt, P. (1998). Endogenous Growth Theory, Cambridge, MA: MIT Press.

[2] Aghion, P., Banerjee, A. and Piketty, T. (1999). 'Dualism and macroeconomic volatility', The Quarterly Journal of Economics, vol. 114, pp. 1359-1397.

[3] Angelopoulos, K., Malley, J. and Philippopoulos, A. (2011a). 'Tax structure, growth and welfare in the UK', Oxford Economic Papers, forthcoming.

[4] Angelopoulos, K., Malley, J. and Philippopoulos, A. (2011b). 'Timeconsistent fiscal policy under heterogeneity: Conflicting or common interests?', CESifo Working Paper Series: 3444.

[5] Bénabou, R. (1996). 'Inequality and growth', in B. Bernanke and J. Rotemberg (eds.), NBER Macroeconomics Annual 1996, pp. 11-92, Cambridge, MA: MIT Press.

[6] Benigno, P. (2009). 'Price stability with imperfect financial integration', Journal of Money, Credit and Banking, vol. 41, pp. 121-149.

[7] Browning, M., Hansen, L. and Heckman, J. (1999). 'Micro data and general equilibrium models', in J. Taylor and M. Woodford (eds.), Handbook of Macroeconomics, vol. 1, pp. 543-633, Amsterdam: Elsevier.

[8] Carceles-Poveda, E. and Giannitsarou, C. (2007). 'Adaptive learning in practice', Journal of Economic Dynamics and Control, vol. 31, pp. 2659-2697.

[9] Carceles-Poveda, E. and Giannitsarou, C. (2008). 'Asset pricing with adaptive learning', Review of Economic Dynamics, vol. 11, pp. 629-651.

[10] Chamley, C. (1986). 'Optimal taxation of capital income in general equilibrium with infinite lives', Econometrica, vol. 54, pp. 607-22.

[11] Chari, V., Lawrence, C. and Kehoe, P. (1994). 'Optimal fiscal policy in a business cycle model', Journal of Political Economy, vol. 102, pp. $617-52$.

[12] Chari, V. and Kehoe, P. (1999). 'Optimal fiscal and monetary policy', in J. Taylor and M. Woodford (eds.), Handbook of Macroeconomics, vol. 1, pp. 1671-1745, Amsterdam: Elsevier. 
[13] Conesa J., Kehoe, T. and Ruhl, K. (2007). 'Modeling great depressions: the depression in Finland in the 1990s', Quarterly Review, Federal Reserve Bank of Minneapolis, Nov., pp. 16-44.

[14] Conesa, J., Kitao, S. and Krueger, D. (2009). 'Taxing capital? Not a bad idea after all!', American Economic Review, vol. 99, pp. 25-48.

[15] Cooley, T. and Hansen, G. (1992). 'Tax distortions in a neoclassical monetary economy', Journal of Economic Theory, vol. 58, pp. 290-316.

[16] Domeij, D. and Heathcote, J. (2004). 'On the distributional effects of reducing capital taxes', International Economic Review, vol. 45, pp. 523554.

[17] Evans, G. and Honkapohja, S. (2001). Learning and Expectations in Macroeconomics. Princeton: Princeton University Press.

[18] Evans, G., Honkapohja, S. and Mitra, K. (2009). 'Anticipated fiscal policy and adaptive learning', Journal of Monetary Economics, vol. 56, pp. 930-953.

[19] Galor, O. and Zeira, J. (1993). 'Income distribution and macroeconomics', Review of Economic Studies, vol. 60, pp. 35-52.

[20] Garcia-Milà, T., Marcet, A. and Ventura, E. (2010). 'Supply side interventions and redistribution', Economic Journal, vol. 120, pp. 105-130.

[21] Giannitsarou, C. (2006). 'Supply-side reforms and learning dynamics', Journal of Monetary Economics, vol. 53, pp. 291-309.

[22] Greulich, K. and Marcet, A. (2008). 'Pareto-improving optimal capital and labor taxes', Unitat de Fonaments de l'Anàlisi Econòmica and Institut d'Anàlisi Econòmica Working Papers, No. 733.08.

[23] Guo, J. and Lansing, K. (1999). 'Optimal taxation of capital income with imperfectly competitive product markets', Journal of Economic Dynamics and Control, vol. 23, pp. 967-995.

[24] Ho, M. and Jorgenson, D. (2001). 'Educational policies to stimulate growth', in G. Harrison, S. Jensen, L. Pedersen and T. Rutherford (eds.), Using Dynamic General Equilibrium Models for Policy Analysis. Amsterdam: North Holland. 
[25] Honkapohja, S. and Mitra, K. (2006). 'Learning stability in economies with heterogeneous agents', Review of Economic Dynamics, vol. 9, pp. 284-309.

[26] Hornstein, A., Krusell, P. and Violante, G. (2005). 'The effects of technical change on labor market inequalities', in P. Aghion and S. Durlauf (eds.), Handbook of Economic Growth, vol. 1, pp. 1275-1370. Amsterdam: Elsevier.

[27] Judd, K. (1985). 'Redistributive taxation in a simple perfect foresight model', Journal of Public Economics, vol. 28, pp. 59-83.

[28] King, R. and Rebelo, S. (1999). 'Resuscitating real business cycles', in J. Taylor and M. Woodford (eds.), Handbook of Macroeconomics, vol. 1, pp. 927-1007, Amsterdam: Elsevier.

[29] Klein, P. (2000). 'Using the generalized Schur form to solve a multivariate linear rational expectations model', Journal of Economic Dynamics and Control, vol. 24, pp. 1405-1423.

[30] Klein, P., Krusell, P. and Ríos-Rull, J. (2008). 'Time-consistent public policy', Review of Economic Studies, vol. 75, pp. 789-808.

[31] Krusell, P., Ohanian, L., Ríos-Rull J. and Violante, G. (2000). 'Capitalskill complementarity and inequality: a macroeconomic analysis', Econometrica, vol. 68, pp. 1029-1053.

[32] Krusell, P. (2002). 'Time-consistent redistribution', European Economic Review, vol. 46, pp. 755-769.

[33] Kydland F. (1995). 'Business cycles and aggregate labor market fluctuations', in T. Cooley (ed.), Frontiers of Business Cycle Research, pp. 126-156, Princeton: Princeton University Press.

[34] Lansing, K. (1999). 'Optimal redistributive capital taxation in a neoclassical growth model', Journal of Public Economics, vol. 73, pp. 423-453.

[35] Lucas, R. (1990). 'Supply-side economics: an analytical review', Oxford Economic Papers, vol. 42, pp. 293-316.

[36] Machin, S. (1996). 'Wage inequality in the UK', Oxford Review of Economic Policy, vol. 12, pp. 47-64. 
[37] Persson, T. and Tabellini, G. (1992). 'The politics of 1992: fiscal policy and European integration', Review of Economic Studies, vol. 59, pp. 689-701.

[38] Schmitt-Grohé, S. and Uribe, M. (1997). 'Balanced-budget rules, distortionary taxes, and aggregate instability', Journal of Political Economy, vol. 105, pp. 976-1000.

[39] Stokey, N. (1996). 'Free trade, factor returns, and factor accumulation', Journal of Economic Growth, Vol. 1, pp. 421-447.

[40] Walker, I. and Zhu, Y. (2008). 'The college wage premium and the expansion of higher education in the UK', Scandinavian Journal of Economics, vol. 110, pp. 695-709.

\section{Appendix: Model Solution}

To solve the model, we start by taking the first-order Taylor series expansion of the DCE and exogenous process for productivity around their respective steady-states. For any variable $X_{t}$, these values are denoted $\widehat{X}_{t}=\log X_{t}-\log X$. We next re-express the model in matrix form as secondorder difference equation system:

$$
\begin{aligned}
& \mathbf{x}_{t}=\mathbf{M}_{1} \mathbf{E}_{t} \mathbf{x}_{t+1}+\mathbf{M}_{2} \mathbf{x}_{t-1}+\mathbf{M}_{3} \mathbf{z}_{t} \\
& \mathbf{y}_{t}=\mathbf{N}_{1} \mathbf{x}_{t}+\mathbf{N}_{2} \mathbf{x}_{t-1}+\mathbf{N}_{3} \mathbf{z}_{t}+\mathbf{N}_{4} \mathbf{E}_{t} \mathbf{x}_{t+1} \\
& \mathbf{z}_{t}=\boldsymbol{\rho} \mathbf{z}_{t-1}+\mathbf{u}_{t}
\end{aligned}
$$

where $\mathbf{x}_{t}=\left[\hat{B}_{c, t+1}, \hat{K}_{c, t+1}, \hat{B}_{s, t+1}, \hat{K}_{s, t+1}\right]^{\prime}$ contains the endogenous state variables; $\mathbf{y}_{t}=\left[\hat{C}_{c, t}, \hat{C}_{s, t}, \hat{C}_{u, t}, \hat{h}_{c, t}, \hat{h}_{s, t}, \hat{h}_{u, t}, \hat{r}_{t}^{b}, \hat{r}_{t}^{k}, \hat{w}_{t}, \hat{w}_{u, t}\right]^{\prime}$ the endogenous control variables; and $\mathbf{z}_{t}=\left[\hat{a}_{t+1}\right]$ the exogenous state variables. ${ }^{30}$ The various $\mathbf{M}$ and $\mathbf{N}$ matrices contain convolutions of the structural parameters calibrated in Table 1. Finally, since we only have one exogenous state variable, $\boldsymbol{\rho}=\rho^{a}$ and $\mathbf{u}_{t}=\varepsilon_{t+1}$.

In what follows we use (22) to briefly describe how we obtain both the rational expectations (RE) and adaptive learning (AL) solutions of the loglinearised model.

\footnotetext{
${ }^{30}$ Other papers in the literature using this particular reduced form are e.g. Giannitsarou (2006) and Carceles-Poveda and Giannitsarou (2007, 2008).
} 


\subsection{Rational expectations}

Employing the undetermined coefficients method, agents first guess that the equilibrium laws of motion for the state variables under $\mathrm{RE}$ have the following linear form:

$$
\mathbf{x}_{t}=\gamma_{\mathbf{x}} \mathbf{x}_{t-1}+\gamma_{\mathbf{z}} \mathbf{z}_{t}
$$

where $\gamma_{\mathbf{x}}$ and $\gamma_{\mathbf{z}}$ are coefficient matrices. Substituting for $\mathbf{z}_{t}$ using the last equation in (22) gives:

$$
\mathbf{x}_{t}=\phi_{\mathbf{x}} \mathbf{x}_{t-1}+\phi_{\mathbf{z}} \mathbf{z}_{t-1}+\phi_{\mathbf{z}} \rho^{-1} \mathbf{u}_{t}
$$

where $\phi_{\mathrm{x}}=\gamma_{\mathrm{x}}$ and $\phi_{\mathrm{z}}=\gamma_{\mathrm{z}} \rho$. Leading (24) by one-period and taking expectations of both sides yields:

$$
\mathbf{E}_{t} \mathbf{x}_{t+1}=\phi_{\mathbf{x}} \mathbf{x}_{t}+\phi_{\mathbf{z}} \rho \mathbf{z}_{t}
$$

since $\phi_{\mathbf{z}} \boldsymbol{\rho}^{-1} \mathbf{E}_{t}\left[\mathbf{u}_{t+1}\right]=0$. Substituting (25) and (24) into the first equation of (22) gives:

$$
\begin{aligned}
\mathbf{x}_{t}= & {\left[\left(\mathbf{I}-\mathbf{M}_{1} \boldsymbol{\phi}_{\mathbf{x}}\right)^{-1} \mathbf{M}_{\mathbf{2}}\right] \mathbf{x}_{t-1}+} \\
& +\left[\left(\mathbf{I}-\mathbf{M}_{1} \boldsymbol{\phi}_{\mathbf{x}}\right)^{-1}\left(\mathbf{M}_{1} \boldsymbol{\phi}_{\mathbf{z}}+\mathbf{M}_{3}\right)\right]\left(\rho \mathbf{z}_{t-1}+\mathbf{u}_{t}\right) .
\end{aligned}
$$

Comparing (26) with (24) implies that the unique RE solution of the reducedform model is given by the two parameter matrices, hereafter denoted by $\bar{\phi}_{\mathbf{x}}$ and $\bar{\phi}_{\mathbf{z}}$, that satisfy the following two equations:

$$
\begin{aligned}
& \phi_{\mathbf{x}}=\left(\mathbf{I}-\mathbf{M}_{1} \phi_{\mathbf{x}}\right)^{-1} \mathbf{M}_{\mathbf{2}} \\
& \phi_{\mathbf{z}}=\left(\mathbf{I}-\mathbf{M}_{1} \phi_{\mathbf{x}}\right)^{-1}\left(\mathbf{M}_{1} \phi_{\mathbf{z}}+\mathbf{M}_{3}\right) \boldsymbol{\rho} .
\end{aligned}
$$

Assuming $\bar{\phi}_{\mathrm{x}}$ and $\bar{\phi}_{\mathrm{z}}$ exist, the solution for the model's state variables under RE is: ${ }^{31}$

$$
\mathbf{x}_{t}=\bar{\phi}_{\mathbf{x}} \mathbf{x}_{t-1}+\rho^{-1} \bar{\phi}_{\mathbf{z}} \mathbf{z}_{t}
$$

Substituting (28) and the expected value of its lead into the second equation of (22) gives the RE solution for the model's control variables:

$$
\begin{aligned}
\mathbf{y}_{t}= & {\left[\mathbf{N}_{1} \bar{\phi}_{\mathbf{x}}+\mathbf{N}_{2}+\mathbf{N}_{4} \bar{\phi}_{\mathbf{x}}^{2}\right] \mathbf{x}_{t-1}+} \\
& +\left[\mathbf{N}_{1} \boldsymbol{\rho}^{-1} \bar{\phi}_{\mathbf{z}}+\mathbf{N}_{3}+\mathbf{N}_{4}\left(\bar{\phi}_{\mathbf{z}}+\bar{\phi}_{\mathbf{x}} \boldsymbol{\rho}^{-1} \bar{\phi}_{\mathbf{z}}\right)\right] \mathbf{z}_{t} .
\end{aligned}
$$

\footnotetext{
${ }^{31}$ The two solution matrices $\bar{\phi}_{x}$ and $\bar{\phi}_{z}$, were obtained applying the method proposed by Klein (2000).
} 


\subsection{Adaptive learning}

Under the AL hypothesis, it is also assumed that private agents can correctly guess the form of the equilibrium policy functions of the state variables given by (23). However, in contrast to the RE solution, it is assumed that they do not know the time-invariant parameter values given by $\bar{\phi}_{\mathbf{x}}$ and $\bar{\phi}_{\mathbf{z}}$, which ultimately govern the dynamics of the economy. ${ }^{32}$ Therefore, they must rely on past data and a recursive learning algorithm to estimate these parameters to produce forecasts of the endogenous state variables for the next period. As new data become available in each period, they revise their parameter estimates so that their forecasting errors are corrected gradually.

More formally, agents' expectations are assumed to follow a so-called perceived law of motion (PLM) of the form:

$$
\mathbf{E}_{t}^{*} \mathbf{x}_{t+1}=\tilde{\phi}_{\mathbf{x}, t-1} \mathbf{x}_{t}+\tilde{\phi}_{\mathbf{z}, t-1} \mathbf{z}_{t}
$$

where parameters $\tilde{\phi}_{\mathrm{x}}$ and $\tilde{\phi}_{\mathrm{z}}$ are the estimates of $\bar{\phi}_{\mathrm{x}}$ and $\bar{\phi}_{\mathrm{z}}$ coming from a recursive least-squares regression and $\mathbf{E}^{*}$ denotes that expectations do not follow the RE hypothesis. ${ }^{33}$

Following a similar procedure as under RE, we substitute (30) into the first equation of (22) to obtain:

$$
\mathbf{x}_{t}=\mathbf{P}_{1} \mathbf{x}_{t-1}+\boldsymbol{\rho}^{-1} \mathbf{P}_{2} \mathbf{z}_{t}
$$

where

$$
\begin{aligned}
& \mathbf{P}_{1}=\left(\mathbf{I}-\mathbf{M}_{1} \tilde{\boldsymbol{\phi}}_{\mathbf{x}, t-1}\right)^{-1} \mathbf{M}_{2} \\
& \mathbf{P}_{2}=\left(\mathbf{I}-\mathbf{M}_{1} \tilde{\boldsymbol{\phi}}_{\mathbf{x}, t-1}\right)^{-1}\left(\mathbf{M}_{1} \tilde{\boldsymbol{\phi}}_{\mathbf{z}, t-1}+\mathbf{M}_{3}\right) \boldsymbol{\rho} .
\end{aligned}
$$

Equation (31) is referred to as the actual law of motion (ALM) since every new observed value of $\mathbf{x}_{t}$ depends on the deep parameters of the model economy but also on the agents' forecasts given by the PLM (30).

The actual laws of motion for the control variables under learning are found by substituting (31) for $\mathbf{x}_{t}$ and (30) for $\mathbf{E}_{t} \mathbf{x}_{t+1}$ in the second equation of (22) giving:

$$
\begin{aligned}
\mathbf{y}_{t}= & {\left[\mathbf{N}_{1} \mathbf{P}_{1}+\mathbf{N}_{2}+\mathbf{N}_{4} \tilde{\phi}_{\mathbf{x}, t-1} \mathbf{P}_{1}\right] \mathbf{x}_{t-1}+} \\
& +\left[\mathbf{N}_{1} \boldsymbol{\rho}^{-1} \mathbf{P}_{2}+\mathbf{N}_{3}+\mathbf{N}_{4}\left(\tilde{\phi}_{\mathbf{x}, t-1} \boldsymbol{\rho}^{-1} \mathbf{P}_{2}+\tilde{\boldsymbol{\phi}}_{\mathbf{z}, t-1}\right)\right] \mathbf{z}_{t} .
\end{aligned}
$$

\footnotetext{
${ }^{32}$ See Evans and Honkapohja (2001) for further details.

${ }^{33}$ Note, we follow the common assumption (see, e.g. Evans and Honkaphoja, 2001, and Carceles-Poveda and Giannitsarou, 2007) that at period $t$ agents form expectations for $\mathbf{x}_{t+1}$ using their estimates from the previous period, $\tilde{\phi}_{\mathbf{x}, t-1}$ and $\tilde{\phi}_{\mathbf{z}, t-1}$, which allows us to avoid a problem of simultaneity in the learning process.
} 
To estimate $\tilde{\phi}_{\mathbf{x}}$ and $\tilde{\phi}_{\mathbf{z}}$ in (30) we first define the matrix $\mathbf{w}_{t}=\left[B_{c, t}\right.$, $\left.K_{c, t}, B_{s, t}, K_{s, t}, a_{t}\right]^{\prime}$ and then use the recursive least-squares (RLS) learning algorithm which can be written for $t=1,2,3 \ldots$, as follows:

$$
\begin{aligned}
& \tilde{\boldsymbol{\phi}}_{t}=\tilde{\boldsymbol{\phi}}_{t-1}+g_{t} \mathbf{R}_{t}^{-1} \mathbf{w}_{t-1}\left(\mathbf{x}_{\mathbf{t}}-\tilde{\boldsymbol{\phi}}_{\mathbf{t}-\mathbf{1}}^{\prime} \mathbf{w}_{t-1}\right)^{\prime} \\
& \mathbf{R}_{t}=\mathbf{R}_{t-1}+g_{t}\left(\mathbf{w}_{t-1} \mathbf{w}_{t-1}^{\prime}-\mathbf{R}_{t-1}\right)
\end{aligned}
$$

where $\mathbf{R}_{t}$ is a matrix with the second moments of the regressors included in $\mathbf{w}_{t} ;\left(\mathbf{x}_{\mathbf{t}}-\tilde{\boldsymbol{\phi}}_{\mathbf{t}-\mathbf{1}}^{\prime} \mathbf{w}_{t-1}\right)$ is the latest forecast error that will be used to correct the current estimates; and $g_{t}=1 / t$ is a decreasing gain sequence implying that, as $t$ increases, every new forecast error will have a lower relative importance in the updating process. ${ }^{34}$

\subsubsection{Initial conditions for learning}

To represent the importance of initial beliefs for the solution of the model under learning, define $\overline{\boldsymbol{\phi}}_{\text {pre }}=\left[\overline{\boldsymbol{\phi}}_{\mathbf{x}, \text { pre }}, \overline{\boldsymbol{\phi}}_{\mathbf{z}, \text { pre }}\right]^{\prime}$ and $\overline{\boldsymbol{\phi}}_{\text {post }}=\left[\overline{\boldsymbol{\phi}}_{\mathbf{x}, \text { post }}, \overline{\boldsymbol{\phi}}_{\mathbf{z}, \text { post }}\right]^{\prime}$ as the RE solution matrices for the pre-reform and post-reform economies, respectively, and $\tilde{\phi}_{0}=\left[\tilde{\phi}_{\mathbf{x}, 0}, \tilde{\phi}_{\mathbf{z}, 0}\right]^{\prime}$ as the matrix containing the starting values of the learning algorithm. To obtain the rational expectations solution, we assume that:

$$
\tilde{\phi}_{0}=\left[\bar{\phi}_{\mathbf{x}, \text { post }}, \bar{\phi}_{\mathbf{z}, \text { post }}\right]^{\prime}
$$

where $\mathbf{R}_{0}$ is the covariance matrix associated with the values of the endogenous state variables as predicted by their corresponding policy functions under the post-reform RE solution $\bar{\phi}_{\text {post }} \cdot{ }^{35}$

For the case of homogeneous learning, we assume, as in Giannitsarou (2006) that:

$$
\tilde{\phi}_{0}=\left[\bar{\phi}_{\mathbf{x}, p r e}, \bar{\phi}_{\mathbf{z}, p r e}\right]^{\prime}
$$

where the covariance matrix $\mathbf{R}_{0}$ is computed as described above, using (36) instead of (35).

\footnotetext{
${ }^{34}$ See, e.g. Evans and Honkapohja (2001) and Honkapohja and Mitra (2006) for details on stability conditions under learning. We make use of Matlab functions made available by Carceles-Poveda and Giannitsarou (2007) to solve the model under AL.

${ }^{35}$ To obtain $\mathbf{R}_{0}$ we make use of a numerical approximation involving the following steps: (i) simulate a series of $N\left(0, \sigma_{a}\right)$ random shocks for the exogenous state variable $a_{t}$, for $T_{\text {num }}=100,000$ periods; (ii) using (i), simulate the values for the endogenous state variables as predicted by their corresponding policy functions under the post reform RE solution $\left(\overline{\boldsymbol{\phi}}_{\text {post }}\right)$ for $T_{\text {num }}$; (iii) construct $\mathbf{w}_{\left(5 \times T_{\text {num }}\right)}$ including the time series of the simulated values for the five states $\left(B_{c, t}, K_{c, t}, B_{s, t}, K_{s, t}, a_{t}\right)$; and (iv) compute the covariance matrix in a recursive fashion according to the second equation of (34), where the starting values $\mathbf{R}_{0}$ and $\mathbf{w}_{0}$ are given by two zero matrices.
} 
For the case of heterogeneous learning, we assume that the skilled workers "guess" that the coefficients remain the same and thus use the coefficients that correspond to the pre-reform economy in their policy functions for the initial period. In contrast, we assume that the capitalists are able to predict the post-reform RE steady-state and their optimal reduced form coefficients for their policy functions in this equilibrium, so that their "guess" for their initial coefficients correspond to the post-reform RE solution. This heterogeneity in beliefs implies that the initial guesses for both agents are effectively incorrect, as the actual economy, as determined by the interaction of their choices, is neither in the pre- nor in the post-reform RE equilibrium. Given the gap between the expected and actual outcomes, both agents use thereafter recursive least-squares to learn the coefficients.

Formally, let $\bar{\phi}_{\mathbf{x}, \text { post }}^{c}$ and $\bar{\phi}_{\mathbf{z}, \text { post }}^{c}$ be a $(4 \times 2)$ and $(1 \times 2)$ sub-matrices of $\bar{\phi}_{\mathbf{x}, \text { post }}$ and $\bar{\phi}_{\mathbf{z}, \text { post }}$, respectively, containing the two columns of $\bar{\phi}_{\mathbf{x}, \text { post }}$ and $\bar{\phi}_{\mathbf{z}, \text { post }}$ that correspond to the policy functions of the capitalists. Similarly, let $\overline{\boldsymbol{\phi}}_{\mathbf{x}, \text { pre }}^{s}$ and $\overline{\boldsymbol{\phi}}_{\mathbf{z}, \text { pre }}^{s}$ be a $(4 \times 2)$ and $(1 \times 2)$ sub-matrices of $\bar{\phi}_{\mathbf{x}, \text { pre }}$ and $\overline{\boldsymbol{\phi}}_{\mathbf{z}, \text { pre }}$, respectively, containing the two columns of $\bar{\phi}_{\mathbf{x}, p r e}$ and $\bar{\phi}_{\mathbf{z}, p r e}$ that correspond to the policy functions of the skilled workers. Hence, $\tilde{\phi}_{0}$ is constructed as:

$$
\tilde{\boldsymbol{\phi}}_{0}=\left[\begin{array}{ll}
{\left[\overline{\boldsymbol{\phi}}_{\mathbf{x}, \text { post }}^{c}\right]_{4 \times 2}} & {\left[\overline{\boldsymbol{\phi}}_{\mathbf{x}, \text { pre }}^{s}\right]_{4 \times 2}} \\
{\left[\overline{\boldsymbol{\phi}}_{\mathbf{z}, \text { post }}\right]_{1 \times 2}} & {\left[\overline{\boldsymbol{\phi}}_{\mathbf{z}, \text { pre }}^{s}\right]_{1 \times 2}}
\end{array}\right]
$$

while, for consistency, $\mathbf{R}_{0}$ is now computed as above but using (37) instead.

Note that for all the post-reform scenarios considered, $\tilde{\phi}_{0}$ always satisfies the stationarity condition that the real parts of all the eigenvalues of $\tilde{\phi}_{\mathbf{x}, 0}$ must lie inside the unit circle, while $\mathbf{R}_{0}$ is always an invertible matrix. These two conditions ensure the algorithm is adequately initialised, see, e.g. Carceles-Poveda and Giannitsarou (2007). 
Figure 1: Laffer curves for changes in $\tau^{k}$
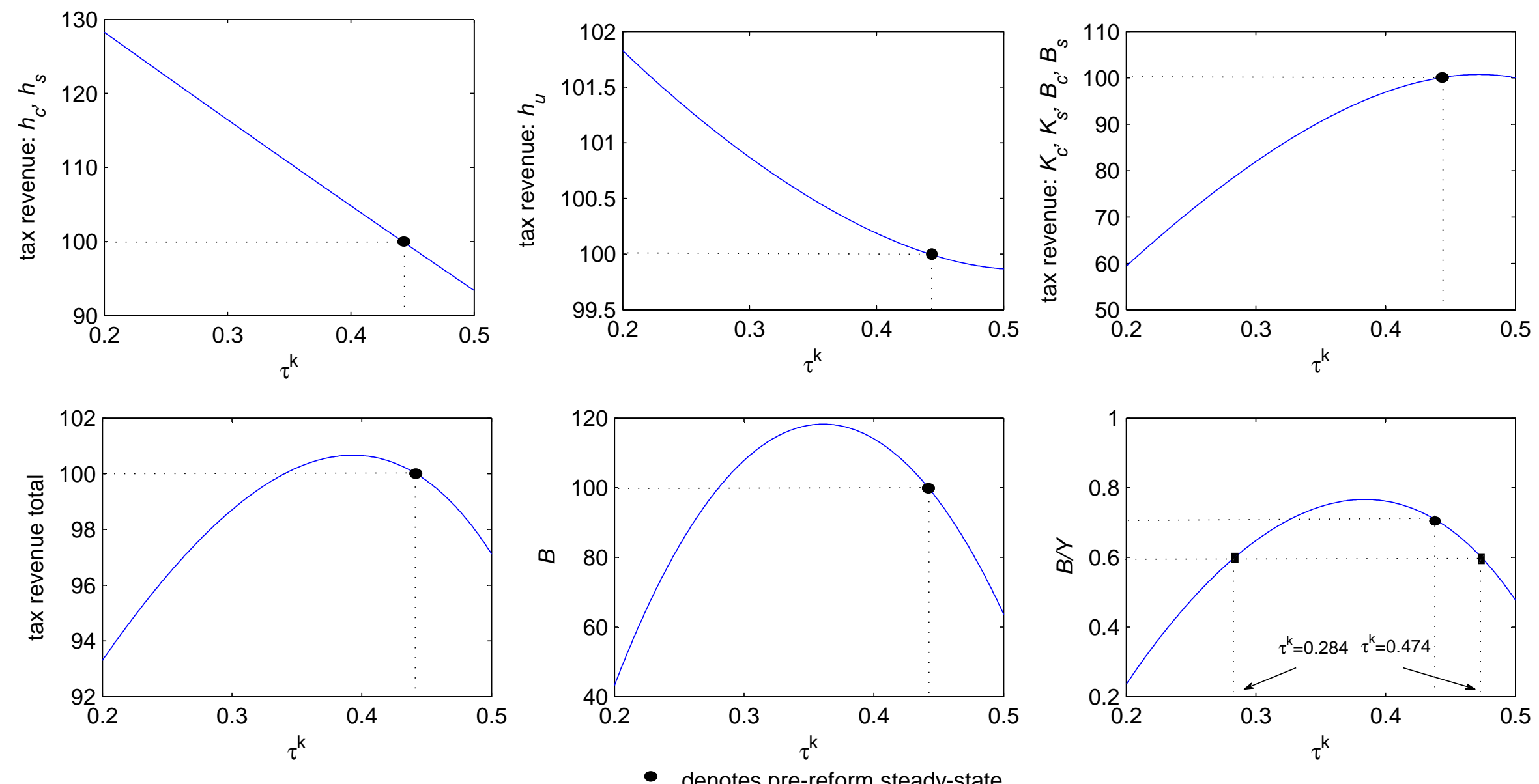

denotes pre-reform steady-state 
Figure 2: Changing the elasticity of substitution between capital and unskilled labour
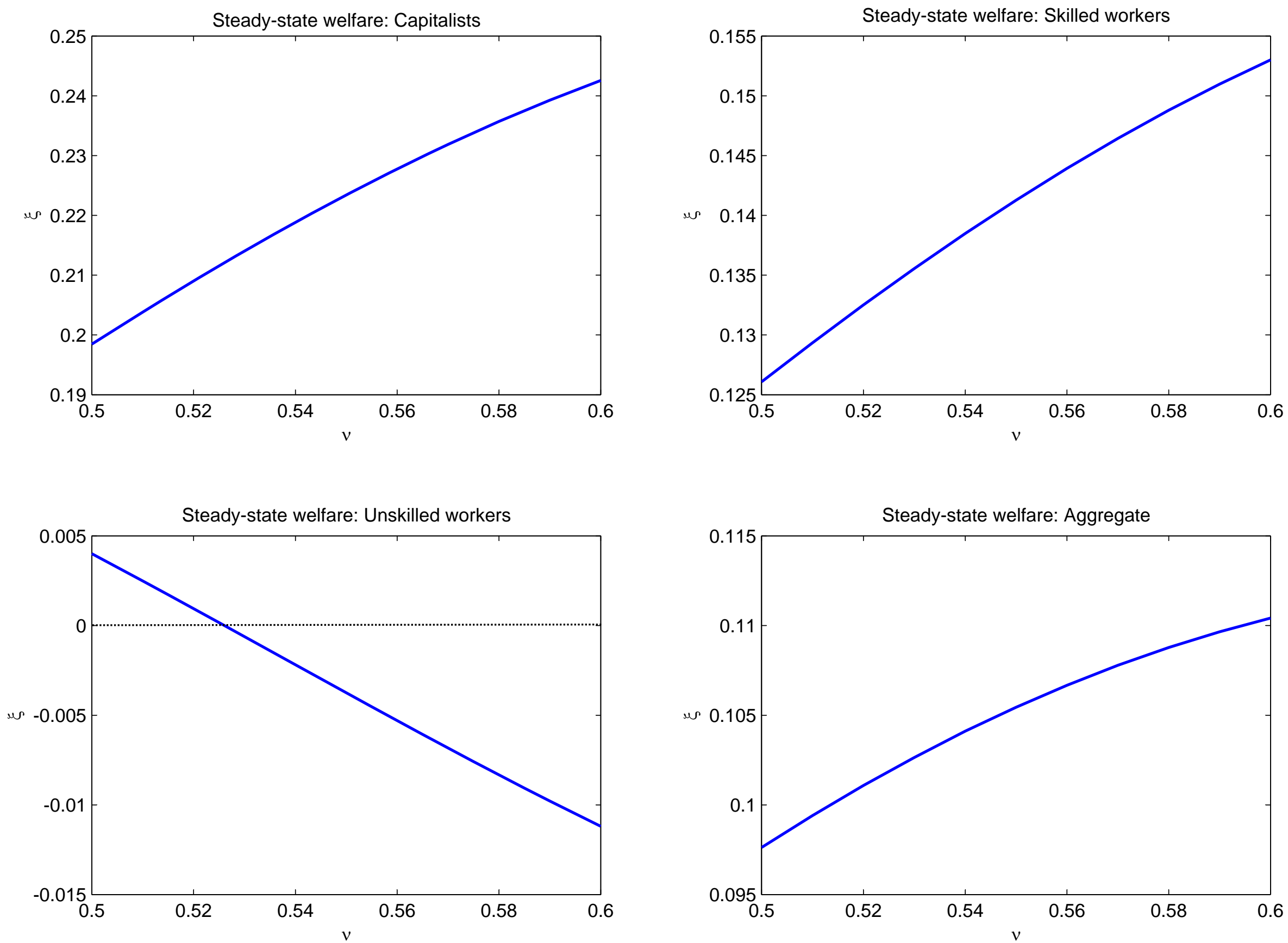

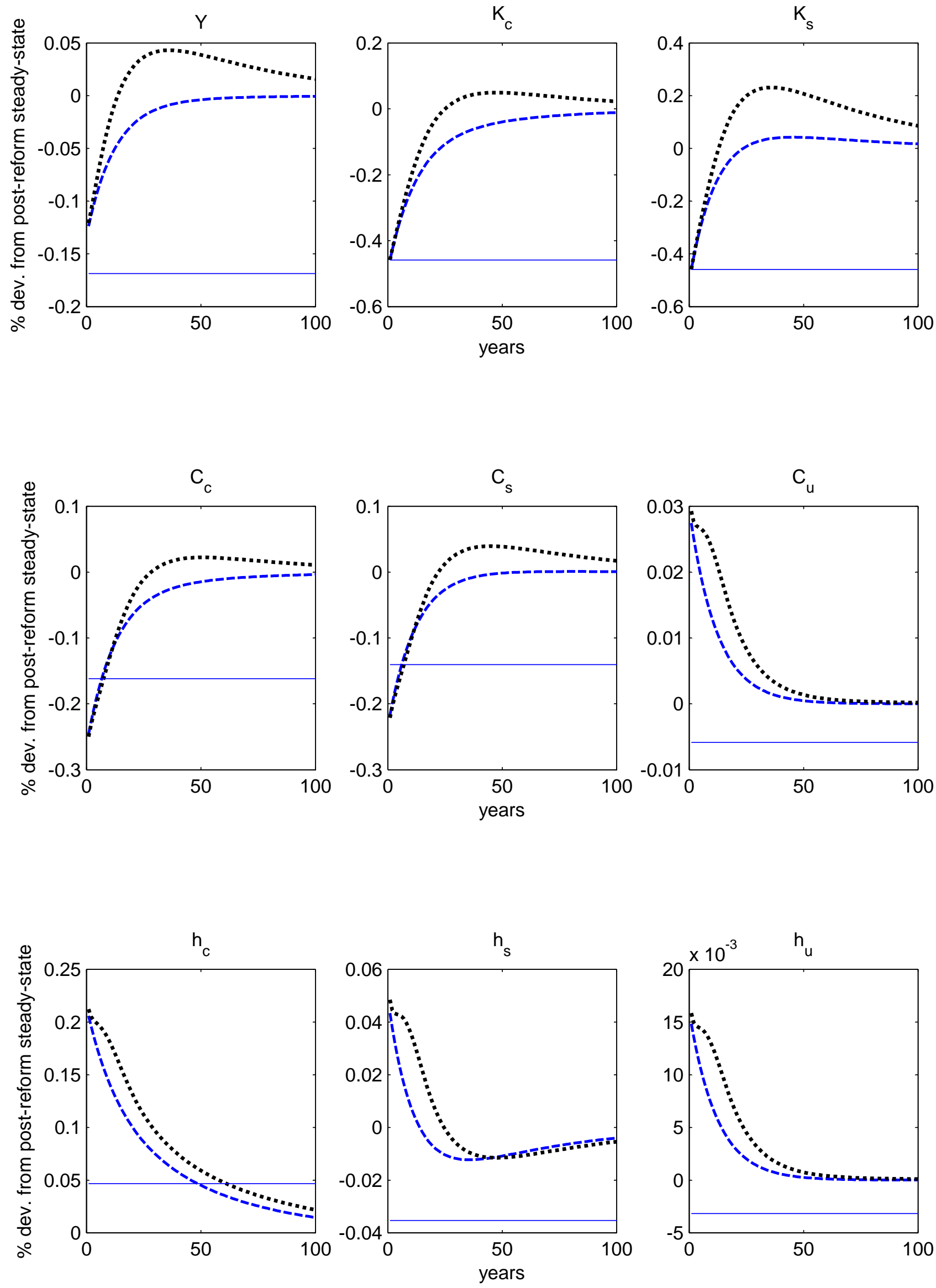